\title{
Electrochemical Biochip for Applications to Wireless and Batteryless Monitoring of Free-Moving Mice
}

\author{
Camilla Baj-Rossi, Giovanni De Micheli and Sandro Carrara*
}

\begin{abstract}
A multi-sensing platform for applications in wireless and batteryless monitoring of free-moving small animals is presented in this paper. The proposed platform hosts six sensors: four biosensors for sensing of both disease biomarkers and therapeutic compounds, and two further sensors ( $T$ and pH) for biosensor calibration. Electrodeposition of Multi-Walled Carbon Nanotubes (MWCNTs) and the subsequent functionalization with proper enzymes is used to assure sensitivity and specificity in electrochemical biosensing. The realized sensors are demonstrated to be capable of measuring several parameters: lactate with a sensitivity of $77 \pm 26 \mu \mathrm{A} / \mathrm{mM} \cdot \mathrm{cm}^{2}$ and a limit of detection (LOD) of $4 \pm 1 \mu \mathrm{M}$; glucose with a sensitivity of $63 \pm 15 \mu \mathrm{A} / \mathrm{mM} \cdot \mathrm{cm}^{2}$ and a LOD of $8 \pm 2 \mu \mathrm{M}$; Etoposide (a well known anti-cancer agent) with a sensitivity of $0.15 \pm 0.04 \mathrm{~mA} / \mathrm{mM} \cdot \mathrm{cm}^{2}$ and a LOD of $4 \pm 1 \mu \mathrm{M}$; Open Circuit Potential (OCP) measurements are used on a Pt/IrOx junction to sense $\mathrm{pH}$ with a sensitivity of around $-75 \pm 5 \mathrm{mV} / \mathrm{pH}$; while a $\mathrm{Pt}$ resistive thermal device is used to measure physiological temperature-range with an average sensitivity of $0.108 \pm 0.001$ $k \Omega /{ }^{\circ} \mathbf{C}$.
\end{abstract}

\section{INTRODUCTION}

Translational medicine makes a quite large use of mice especially as good and low-cost models of mammalian regulators function by monitoring, e.g., the ATP [1]. Monitoring free-moving animal is an extremely good approach because translational medicine may monitor the disease evolution in a more natural dynamics by following the animal models in a situation with reduced stress. Of course, batteries are not allowed on board due to size constrains when dealing with very small animals. Batteryless passive systems are easily possible in animal monitoring because the implant does not require any on-board power consumption [2]. On the other hand, the use of cameras mounted on the mouse cage provides lowcost solutions for continuous monitoring of the behavior of free-moving mice [3]. However, active devices are definitely required if we want to integrate biosensors on the implant and, therefore, systems for wireless power delivery in mouse telemetry have been proposed few years ago [4]. This new advance opened the possibility to develop active systems for continuous monitoring of free-moving mice even dealing with metabolites detection. New systems have been then proposed for monitoring of free-moving mice dealing with blood pressure [5], body temperature and heart pulse [6]; while remotely powered detection of $\mathrm{pH}$ was demonstrated too [7]. Also the possibility of multi-channel devices has

*Corresponding author: sandro.carrara@epfl.ch

Laboratory of Integrated Systems, Swiss Federal Institute of Technology (EPFL), Lausanne, Switzerland

The SNF Sinergia Project (CRSII2_147694/1) and NanoSys project within the frame of the UE program ERC-2009-AdG-246810, financially supported this research. been demonstrated though only limited to applications in ECG acquisitions [8]. These very recent developments show detection of bio-signals but not metabolites. For molecular metabolites the story is quite different because it is typically needed to involve enzymes-based biosensors that require more complex integration of bio-membranes and electronics. In the area of metabolism monitoring in small animals, the most successful development is the monitoring of glucose in mice [9], even with implants remaining in-vivo up to 56 days [10]. More recent devices have shown detection of other endogenous metabolites (e.g., lactate, glutamate, and ATP) [11] though not within the same sensing platform. However, all these more recent developments still present electrical cables through the animals' skin [9]-[12], which allow only limited movement in the animal cage. In 2012, a novel system to transmit power and receive data on completely free-moving animals has been proposed [13], and at the end of last year the possibility of the integration with a fully implantable and biocompatible multi-panel array sensor has been proposed [14]. Aim of the present paper is to present the most recent outputs toward the development of this novel multi-array sensor platform and to demonstrate the feasibility to detect several endogenous metabolites (e.g., glucose, lactate) and drugs (e.g., etoposide (ETO), mitoxantrone (MTX), and etodolac (ETD) together with the sensing of $\mathrm{pH}$ and temperature for biosensors calibration. The biosensors were, in some cases, then functionalized with specific enzymes to assure specificity and MWCNT to assure high sensitivity for lactate and glucose [15] as well as for drugs [16]. This passive platform is tested here with laboratory equipment meanwhile it is built to be coupled with an active and fully implantable potentiostat [17] and with a a wireless powering system for power and data transmission, for further applications in implantable devices for monitoring of freemoving mice in a cage.

\section{MATERIALS AND METHODS}

\section{A. Application scenario}

The fully-implantable device consists of three main building blocks: 1) a passive sensing platform, 2) integrated circuits (ICs) to perform electrochemical measurements and 3) a coil for power supply and data transmission. Fig. 1 shows a photograph of the implantable device after the assembly of the different components. The device in Fig. 1 is a not-working prototype that was intended to test the biocompatibility of the materials used [14]. This work will present a complete in-vitro characterization of the passive platform, while the electronics measurements for data communication 


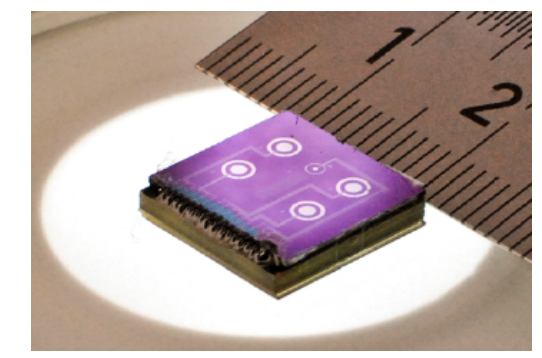

Fig. 1. Photograph of the implantable chip after the assembly of the components.

and remote powering are reported in another article [18].

\section{B. Passive Chip Microfabrication}

Microfabrication was realized at the EPFL Centre of Micronano Technology (CMI). Silicon wafers with $500 \mathrm{~nm}$ of native oxide were chosen as substrate. Chip metalization was realized by evaporation of $10 \mathrm{~nm}$ of $\mathrm{Ti}$, followed by $100 \mathrm{~nm}$ of Pt. Metal passivation was made via atomic layer deposition of $\mathrm{Al}_{2} \mathrm{O}_{3}$, followed by dry etching with Argon Ion Milling. More details on the microfabrication can be found in [14].

\section{Materials}

MWCNTs ( $\sim 10 \mathrm{~nm}$ diameter and $\sim 1-2 \mu \mathrm{m}$ length) with $5 \%-\mathrm{COOH}$ groups content, were purchased as a powder from DropSens (Spain). MWCNTs in powder were dispersed in a chitosan solution $(0.7 \% \mathrm{w} / \mathrm{v}) \mathrm{pH} 5$ and then sonicated for $3 \mathrm{~h}$ to obtain a $8 \mathrm{mg} / \mathrm{ml}$ dispersion. All experiments were carried out in a $100 \mathrm{mM}$ phosphate buffered saline solution (PBS, pH 7.4) as supporting electrolyte. Lactate oxidase (LOx) from Pediococcus species and glucose oxidase (GOx) from Aspergillus Niger were purchased from Roche in lyophilizate powder and dissolved in a $100 \mathrm{mM}$ PBS (pH 7.4). Lithium L-lactate and D-(+)-glucose (SigmaAldrich, Switzerland) in powder and dissolved in in PBS. The drugs ETO, MTX and ETD purchased as a powder (Sigma-Aldrich) were dissolved in Dimethyl sulfoxide due to their low solubility in water. For the $\mathrm{pH}$ sensor, a solution of Iridium(IV) chloride hydrate $(99.9 \%$ metals basis, from Sigma Aldrich), $\mathrm{H}_{2} \mathrm{O}_{2}$ (30\%), oxalic acid dihydrate (98\%, from Sigma Aldrich), and potassium carbonate anhydrous (99\%, from Alfa Aesar) was prepared for the deposition of the Iridium Oxide film (IrOx), as described in [19].

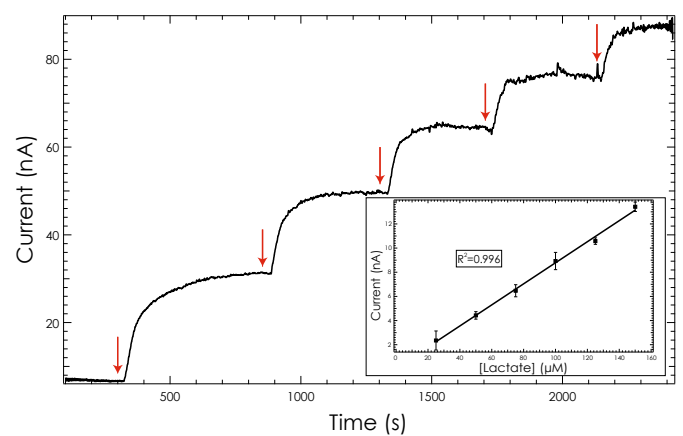

Fig. 2. Calibration line of lactate detection in CA (at a fix potential of +650 $\mathrm{mV}$ ) after functionalization with MWCNTs and LOx. Error bars correspond to the standard deviation for 3 different measurements (confidence interval $95.4 \%)$.

\section{Electrode preparation and functionalization}

For the detection of lactate and glucose in chronoamperometry (CA), working electrodes were functionalized by electrodeposition of a chitosan/MWCNT dispersion $8 \mathrm{mg} / \mathrm{ml}$ as described in [14]. For glucose and lactate measurements, we used working electrodes (WEs) with a diameter of 500 $\mu \mathrm{m}$ and $1.2 \mathrm{~mm}$, respectively. A $33 \mathrm{mg} / \mathrm{ml}$ solution of LOx, or, alternatively, a $15 \mathrm{mg} / \mathrm{ml}$ solution of GOx, was drop cast on some working electrodes and stored overnight at $4^{\circ} \mathrm{C}$. For the measurements in the presence of drugs with cyclic voltammetry $(\mathrm{CV})$, the electrodes were used without modifications. For the $\mathrm{pH}$ sensor, we used a working electrode of $300 \mu \mathrm{m}$ diameter. A layer of IrOx was created on the electrode surface by applying a constant current of $0.94 \mu \mathrm{A}$ for $500 \mathrm{~s}$. After 2 days of stabilization in PBS $\mathrm{pH}$ 7.4 to reduce the potential drift, the electrodes were tested for $\mathrm{pH}$ sensing. All the samples were freshly prepared and used the same day. When not in use, electrodes were stored at $4^{\circ} \mathrm{C}$.

\section{E. Electrochemical Measurements}

To test the passive sensing platform, electrochemical measurements were performed using an Autolab electrochemical workstation (Metrohm, Switzerland). Electrodes were tested for lactate and glucose sensitivity with CA at $+650 \mathrm{mV}$. The sensors were first dipped in a $100 \mathrm{mM}$ PBS solution ( $\mathrm{pH} 7.4$ ), under stirring conditions, then conditioned for 1 $\mathrm{h}$ at $+650 \mathrm{mV}$ and then tested against repeated injections of lactate $25 \mu \mathrm{M}$, or glucose $50 \mu \mathrm{M}$. CV was used to identify the oxidation/reduction peaks of ETO, MTX and ETD. CV was performed at room temperature under aerobic conditions by applying a triangular waveform voltage in the range between $-700 \mathrm{mV}$ and $+700 \mathrm{mV} v s$. $\mathrm{Pt}$ and a scan rate of $20 \mathrm{mV} / \mathrm{s}$. After an initial conditioning in PBS, which consists of 30' of continuous cycling, drops of $400 \mu \mathrm{l}$ of ETO or MTX solutions were added at the right concentration. $\mathrm{pH}$ was computed averaging the open circuit potential (OCP) by continuously changing the $\mathrm{pH}$ of the buffer solution by adding an acid or a basic solution ( $\mathrm{HCl}$ and $\mathrm{NaOH}$, respectively). The $\mathrm{pH}$ was monitored by means of an external $\mathrm{pH}$ meter (from VWR). An external reference electrode (double junction in $\mathrm{Ag} \mid \mathrm{AgCl}$ ) was used in

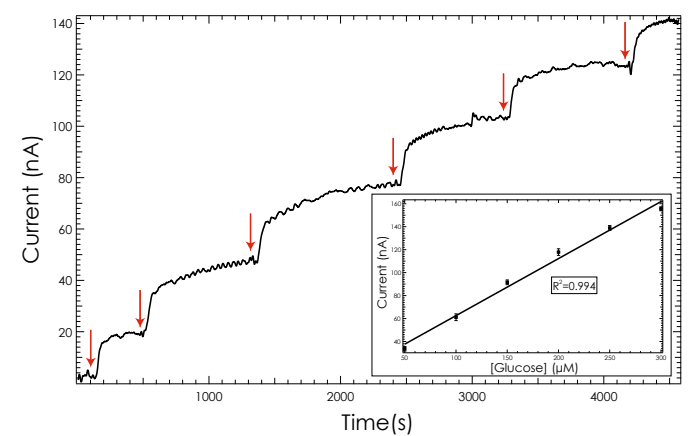

Fig. 3. Calibration line of glucose detection in CA (at a fix potential of +650 $\mathrm{mV}$ ) after functionalization with MWCNTs and GOx. Error bars correspond to the standard deviation for 3 different measurements (confidence interval $95.4 \%)$. 


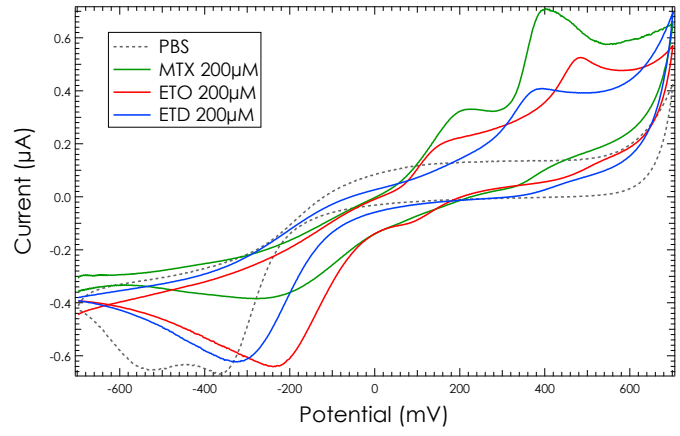

Fig. 4. Cyclic voltammograms of a bare electrode in PBS, in the presence of MTX $200 \mu \mathrm{M}$, ETO $200 \mu \mathrm{M}$ or ETD $200 \mu \mathrm{M}$.

order to have stable and reproducible measurements. For the temperature sensor, a Fluke $87 \mathrm{~V}$ Industrial multimeter (by Fluke) was connected to our platform to measure the changes in resistivity. Sensitivity and limit of detection (LOD) are the key parameter used to evaluate the sensing performances. Sensitivity per unit area was computed from the slope of the straight line obtained by plotting the current increases $v s$. glucose, lactate or drug concentration. The LOD was computed as three times the signal-to-noise ratio according to the expression $L O D=k \frac{\delta i}{S}$, where $\delta i$ is the standard deviation of the blank measurements, $S$ is the sensitivity, and $k$ is a parameter accounting for the confidence level $(\mathrm{k}=1$, 2 , or 3 corresponds to $68.2 \%, 95.4 \%$, or $99.6 \%$ of statistical confidence) [20].

\section{RESULTS AND DISCUSSION}

\section{A. Measurements of metabolites and anti-cancer drugs}

After the electrodeposition of MWCNTs in chitosan and the functionalization of the WE with the enzyme, electrodes were tested for lactate and for glucose sensitivity with CA at $+650 \mathrm{mV}$. The CA measurements at $+650 \mathrm{mV}$ for lactate and glucose are reported in Fig. 2 and Fig. 3, respectively. The arrows correspond to repeated injections of lactate $25 \mu \mathrm{M}$ or glucose $50 \mu \mathrm{M}$, respectively. Well-defined current steps are visible every further injection. The calibration lines reported in the insets of Fig. 2 and Fig. 3 are calculated from the evaluation of the current steps, by measuring the difference between the reached current value and the baseline. For lactate we obtained a sensitivity of $77 \pm 26 \mu \mathrm{A} / \mathrm{mM} \cdot \mathrm{cm}^{2}$ and a LOD of $4 \pm 1 \mu \mathrm{M}$, while for glucose we obtained a sensitivity of $63 \pm 15 \mu \mathrm{A} / \mathrm{mM} \cdot \mathrm{cm}^{2}$ and a LOD of $8 \pm 2 \mu \mathrm{M}$, which fits with many clinical applications [21]. Calibration of glucose and lactate at higher physiological concentrations will require the adoption of a system of membranes, as reported in [22], and it will be the object of our future investigations. However, with our sensing platform, we can monitor many other metabolites of clinical interest (e.g. glutamate, ATP), by changing the enzyme.

The anti-cancer drugs ETO and MTX, and the antiinflammatory drug ETD were monitored with $\mathrm{CV}$. CV has been widely used to detect electroactive drugs in biological fluids [23]. As reported in previous studies [24]-[26], ETO, MTX and ETD are electro-active compounds that give in $\mathrm{CV}$ well-defined oxidation peaks in the potential window

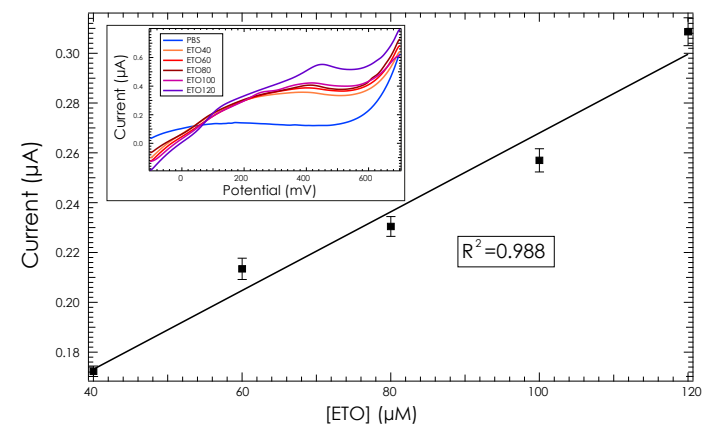

Fig. 5. Calibration curve for ETO within the physiological range in PBS, obtained in CV. Error bars correspond to the standard deviation for 4 different measurements (confidence interval 95.4\%). The inset shows the oxidation peak currents increasing with the drug concentration.

between $+100 \mathrm{mV}$ and $+700 \mathrm{mV}$. Fig. 4 shows the cyclic voltammograms for a bare electrode $(500 \mu \mathrm{m}$ diameter $)$ in PBS or in the presence of $200 \mu \mathrm{M}$ MTX, or $200 \mu \mathrm{M}$ ETO or $200 \mu \mathrm{M}$ ETD. According to literature, the voltammograms show two defined oxidation peaks for ETO (at $+200 \mathrm{mV}$ and $+500 \mathrm{mV}$ vs. Pt), two oxidation peaks for MTX (at $+250 \mathrm{mV}$ and $+450 \mathrm{mV}$ vs. Pt), and an oxidation peak for ETD (at $+350 \mathrm{mV}$ vs. Pt). With bare electrodes, we also performed $\mathrm{CV}$ measurements to calibrate the sensors for ETO within the therapeutic range. Fig. 5 shows the dependence of the peak current on ETO concentrations. The y-axis values are the peak values of the current peaks centered at $+500 \mathrm{mV}$. The inset in Fig. 5 shows the linear increase in current of the oxidation peaks at various ETO concentrations, with a sensitivity of $0.15 \pm 0.04 \mathrm{~mA} / \mathrm{mM} \cdot \mathrm{cm}^{2}$ and a LOD of $4 \pm 1$ $\mu \mathrm{M}$, which fits ETO therapeutic range (33.9-101.9, [27]). These results prove that the sensing platform is capable to monitor drugs and metabolites within their therapeutic or physiological ranges.

\section{B. Temperature sensor}

The temperature sensor is a resistive thermal device (RTD) that consists of a $\mathrm{Pt}$ wire of $4 \mu \mathrm{m}$ width and $93 \mathrm{~mm}$ length, with an average resistivity of $34 k \Omega$ at $20^{\circ} \mathrm{C}$. We chose $\mathrm{Pt}$ since it is commonly used for resistive thermal devices and because, among other metals Pt represents the best tradeoff between linear behavior, higher metal resistivity and biocompatibility [28]. Fig. 6 shows the response of the PtRTD upon different temperatures in PBS. The temperature was first increased from $35^{\circ} \mathrm{C}$ to $42^{\circ} \mathrm{C}$ (forward scan) and then was inversely changed (backward scan), showing a linear behavior with an average sensitivity of $0.108 \pm 0.001$ $k \Omega /{ }^{\circ} \mathrm{C}$, which is compatible with the theoretical value of $0.13 \mathrm{k} \Omega /{ }^{\circ} \mathrm{C}$ (calculated from the temperature coefficient of resistivity for $\mathrm{Pt}, \alpha=0.00385^{\circ} \mathrm{C}^{-1}$ ).

\section{C. $p H$ sensor}

IrOx is a well-known biocompatible material already used in the creation of implantable electrodes [19]. The OCP of an $\mathrm{IrOx}$ film changes in a predictable manner according to the $\mathrm{pH}$ of the solution. Fig. 7 shows the calibration of the $\mathrm{pH}$ sensor measured in the $\mathrm{pH}$ range from 5 to 9 . The $\mathrm{pH}$ of the buffer solution was continuously monitored with an 


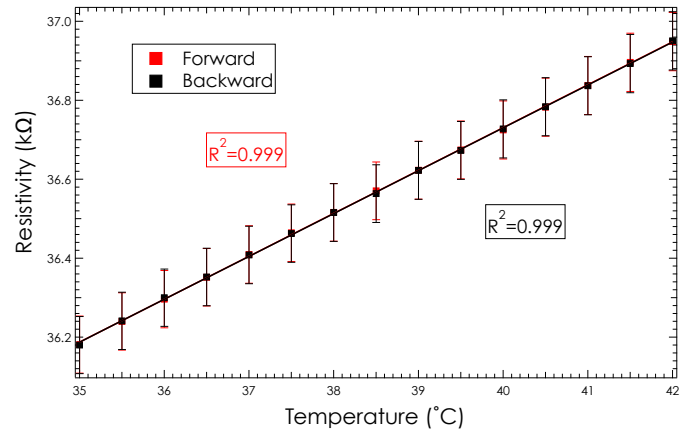

Fig. 6. Calibration curve for the temperature sensor. Error bars correspond to the standard deviation for 9 different measurements (confidence interval $95.4 \%)$.

external $\mathrm{pH}$ meter and the corresponding OCP was measured for the forward scan (pH from 5 to 9) and for the backward scan ( $\mathrm{pH}$ from 9 to 5). In the considered range, the potential changes linearly with increasing $\mathrm{pH}$, with a sensitivity of $74 \pm 3 \mathrm{mV} / \mathrm{pH}$ for the forward scan, and $-75 \pm 5 \mathrm{mV} / \mathrm{pH}$ for the backward scan. Our sensor with the IrOx film showed a near super-Nernstian response with sensitivity values similar to the ones reported in [19].

\section{CONCLUSIONS}

Aim of the present paper was to present the most advanced developments of a novel multi-array sensor platform for further applications in monitoring of free-moving mice. The paper demonstrated the feasibility of the multi-panel platform for acquiring data among several endogenous metabolites related to animal metabolism as well as several exogenous compounds, typically therapeutic drugs. The platform also demonstrated the reliability of the acquired data by hosting sensors for data calibration. The detection of glucose, lactate, ETO, MTX, and ETD is shown as proof of the platform capability for metabolism monitoring, while the detection of $\mathrm{pH}$ and temperature is shown as proof of biosensors calibration. The passive sensing platform presented in this work is built to be integrated into a fully-implantable device for further applications in monitoring of mice that are free to move in a cage. In particular, the device will be used to monitor concentrations of drugs and disease biomarkers in interstitial tissues of very small animals.

\section{ACKNOWLEDGMENT}

Sara S. Ghoreishizadeh, Enver G. Kilinç, Catherine Dehollain, Tanja Rezzonico Jost and Fabio Grassi are acknowledged for useful discussions on the design of the passive platform.

\section{REFERENCES}

[1] U. Schenk, M. Frascoli, M. Proietti, R. Geffers, E. Traggiai, J. Buer, C. Ricordi, A. M. Westendorf, and F. Grassi, Science signaling, vol. 4, no. 162, p. ra12, 2011.

[2] T. Kaya and H. Koser, in IEEE RFID Eurasia, 1st Annual, 2007, pp. $1-4$.

[3] G. Stamatescu, K. Romer, R. Ludwig, S. M. Ibrahim, and V. Sgârciu, in IEEE DCOSS, 2011, pp. 1-3.

[4] D. Russell, D. McCormick, A. Taberner, P. Nielsen, P. Hu, D. Budgett, M. Lim, and S. Malpas, in IEEE BioCAS 2009, pp. 273-276.

[5] P. Cong, N. Chaimanonart, W. H. Ko, and D. J. Young, Solid-State Circuits, IEEE J., vol. 44, no. 12, pp. 3631-3644, 2009.

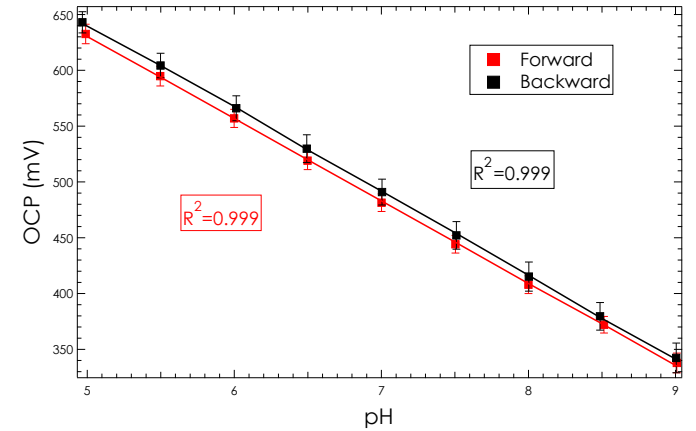

Fig. 7. Open circuit potential of the IrOx coated electrode to different $\mathrm{pH}$. Error bars correspond to the standard deviation for 9 different measurements (confidence interval 95.4\%).

[6] N. Chaimanonart and D. J. Young, in IEEE EMBC 2009, pp. 48724875.

[7] H. Cao, V. Landge, U. Tata, Y.-S. Seo, S. Rao, S.-J. Tang, H. Tibbals, S. Spechler, and J. Chiao, Biomed. Engin., IEEE Trans., vol. 59, no. 11, pp. 3131-3139, 2012.

[8] C.-C. Liu, E. O'Connor, and K. P. Strohl, Sensors Journal, IEEE, vol. 6, no. 1, pp. 187-202, 2006.

[9] U. Klueh, Z. Liu, B. Cho, T. Ouyang, B. Feldman, T. P. Henning, M. Kaur, and D. Kreutzer, Diabet. techn.\& ther, vol. 8, no. 3, pp. 402-412, 2006.

[10] B. Yu, N. Long, Y. Moussy, and F. Moussy, Biosens. Bioelectr., vol. 21, no. 12, pp. 2275-2282, 2006.

[11] S. Carrara, L. Bolomey, C. Boero, A. Cavallini, E. Meurville, G. De Micheli, T. R. Jost, M. Proietti, and F. Grassi, Sensors Journal, IEEE, vol. 13, no. 3, pp. 1018-1024, 2013.

[12] U. Klueh, Z. Liu, B. Feldman, T. P. Henning, B. Cho, T. Ouyang, and D. Kreutzer, J. Diabetes Sci. Technol., vol. 5, no. 3, pp. 583-595, 2011.

[13] E. G. Kilinc, F. Maloberti, and C. Dehollain, in IEEE BioCAS 2012, pp. 260-263.

[14] C. Baj-Rossi, E. G. Kilinc, S. S. Ghoreishizadeh, D. Casarino, T. R. Jost, C. Dehollain, F. Grassi, L. Pastorino, G. De Micheli, and S. Carrara, in IEEE BioCAS 2013, pp. 166-169.

[15] C. Boero, S. Carrara, G. Del Vecchio, L. Calzà, and G. De Micheli, NanoBioscience, IEEE Trans., vol. 10, no. 1, pp. 59-67, 2011.

[16] S. Carrara, A. Cavallini, V. Erokhin, and G. De Micheli, Biosens. Bioelectr., vol. 26, no. 9, pp. 3914-3919, 52011.

[17] S. Ghoreishizadeh, E. G. Kilinc, C. Baj-Rossi, G. De Micheli, C. Dehollain, and S. Carrara, in IEEE BioCAS 2013., pp. 218 - 221.

[18] C. Baj-Rossi, G. E. Kilinc, S. S. Ghoreishizadeh, D. Casarino, J. T. Rezzonico, C. Dehollain, F. Grassi, L. Pastorino, G. De Micheli, and S. Carrara, IEEE Transaction on Biomedical Circuits and Systems, 2014, Submitted.

[19] I. A. Ges, B. L. Ivanov, D. K. Schaffer, E. A. Lima, A. A. Werdich, and F. J. Baudenbacher, Biosens. Bioelectr, vol. 21, no. 2, pp. 248-256, 2005.

[20] J. Mocak, A. Bond, S. Mitchell, and G. Scollary, Pure Appl. Chem., vol. 69, no. 2, pp. 297-328, 1997.

[21] V. H. Routh, Physiol. behav., vol. 76, no. 3, pp. 403-413, 2002.

[22] S. P. Nichols, A. Koh, W. L. Storm, J. H. Shin, and M. H. Schoenfisch, Chemical reviews, vol. 113, no. 4, pp. 2528-2549, 2013.

[23] N. Abo El-Maali, Bioelectrochem, vol. 64, no. 1, pp. 99-107, 2004.

[24] J. Holthuis, W. Van Oort, F. Römkens, J. Renema, and P. Zuman, J. Electroanal. Chem. Interf. Electrochem., vol. 184, no. 2, pp. 317-329, 1985.

[25] A. Oliveira Brett, T. Macedo, D. Raimundo, M. Marques, and S. Serrano, Anal. chim. acta, vol. 385, no. 1, pp. 401-408, 1999.

[26] S. Ylmaz, B. Uslu, and S. A. Özkan, Talanta, vol. 54, no. 2, pp. 351-360, 2001.

[27] J. J. Holthuis, P. E. Postmus, W. J. Van Oort, B. Hulshoff, H. Verleun, D. T. Sleijfer, and N. H. Mulder, Europ. J. Canc. Clin. Onc., vol. 22, no. 10, pp. 1149-1155, 1986.

[28] R. I. Frank and T. E. Salzer, U.S. Patent No. 4,129,848., 121978. 